\title{
Ferrugem do pessegueiro e seu efeito na desfolha e na concentração de carboidratos em ramos e gemas
}

\author{
Giselda Alves, Louise L. May-De Mio, Flavio Zanette \& Marisa C. Oliveira \\ Departamento de Fitotecnia e Fitossanitarismo, Universidade Federal do Paraná, 80035-050, Curitiba, PR, Brasil
}

Autor para correspondência: Louise Larissa May-De Mio, e-mail: maydemio@ufpr.br

\section{RESUMO}

Este trabalho teve por objetivo avaliar as relações entre a intensidade de ferrugem (incidência e severidade), a indução da doença na desfolha e o nível total de carboidratos nas gemas e ramos em pessegueiros "Chimarrita” na região subtropical do Brasil (Curitiba Paraná). A variação da intensidade de ferrugem foi gerada partir de quatro períodos de pulverização (sem pulverização; pulverização com fungicida de dezembro até janeiro; dezembro a fevereiro e de dezembro a abril) e o experimento foi conduzido em dois anos com seis repetições por tratamento. A desfolha, incidência e severidade foram avaliadas ao longo do tempo em dois ramos mistos, de um ano, marcados em lados opostos de cada árvore. Carboidratos foram analisados duas vezes no ano (março e maio) pelo método do fenol sulfúrico (absorbância a $490 \mathrm{~nm}$ ). AACPD em 2005 foi aproximadamente duas vezes o valor de 2004 na testemunha e todos os demais tratamentos diferiram da testemunha. A correlação positiva foi observada entre a severidade e desfolha indicando uma interferência efetiva do patógeno no processo de desfolha em regiões subtropicais. O nível de carboidratos solúvel total em ramos com gemas no tratamento com pulverização de dezembro-abril foi maior do que o nível da testemunha, mostrando a importância da desfolha depois da colheita.

Palavras-chave: Tranzschelia discolor, incidência, severidade.

\begin{abstract}
Peach rust and its effect on the defoliation and carbohydrate concentration in branches and buds

This work aimed to evaluate the relationships between rust intensity (incidence and severity), disease induced defoliation and total carbohydrate level in buds and brushes of "Chimarrita" peach trees in a Brazilian subtropical region (Curitiba, Paraná). Rust intensity range was generated by four fungicide-spraying treatments (non-spraying; regular fungicide spraying from December to January; December to February and December to April) and the experiments were carried out over two years and six replications per treatment. Defoliation, incidence and severity were assessed over time in two previously marked one-year-old mixed branches, each one on opposite sides of each tree. Carbohydrates were analyzed twice each year (March and May) by sulphuric phenol method (absorbance at $490 \mathrm{~nm}$ ). AACPD in 2005 was nearly twice as high as that of 2004 for the control, and all other treatments differed from the control. A positive correlation was observed between severity and defoliation, indicating effective pathogen interference in peach trees' defoliation process in the subtropical region. Total soluble carbohydrate levels in branches with no buds of the December-April spraying treatment were higher than the nonspraying treatment levels, showing the importance of post-harvest defoliation.
\end{abstract}

Keywords: Tranzschelia discolor, incidence, severity.

\section{INTRODUÇÃO}

A ferrugem, causada pelo fungo Tranzschelia discolor (Fuckel) Tranzschel \& M.A. Litv., é uma das principais doenças da cultura do pessegueiro em regiões subtropicais. A região sul do Paraná concentra grande parte da produção do Estado e, ao longo dos anos, a ferrugem vem aumentando, possivelmente devido a condições climáticas favoráveis na primavera e no verão, além do controle da doença ser realizado, na maioria das vezes, somente a partir de janeiro

Parte da Dissertação de Mestrado do primeiro autor. Universidade Federal do Paraná. Curitiba PR. 2006. quando a epidemia já iniciou, favorecendo o aumento do inóculo de um ano para o outro (May-De Mio et al., 2004).

O patógeno $T$. discolor é macrocíclico e heteróico, apresentando normalmente três tipos de esporos: aeciósporos, urediniósporos e teliósporos. Entretanto, em pessegueiro a ferrugem apresenta freqüentemente apenas urediniósporos, sendo rara a formação de teliósporos (Smith, 1947). O fungo sobrevive na forma de micélio dormente em cancros dos ramos de pessegueiros infectados. A infecção primária, nas nossas condições, é originada por urediniósporos que sobreviveram no inverno nas pústulas dos cancros dos ramos. Durante a primavera urédias marrons ferruginosas rompem a epiderme dos ramos para liberar os urediniósporos (Goldsworthy \& Smith, 1931) que são disseminados por meio do vento, chuvas e insetos. 
Em casos de alta severidade da doença, pode-se observar um desfolhamento quase completo da planta (Martins \& Amorim, 1996), reduzindo a capacidade de absorção de $\mathrm{CO}_{2}$ e de luz e diminui o processo fotossintético. No período de pós-colheita é importante a manutenção da folha na planta, uma vez que o total de carboidratos armazenados para o próximo ciclo de produção depende da duração da folhagem para a realização da fotossíntese e conseqüente armazenamento de nutrientes (Bleicher \& Tanaka, 1982).

Yoshioka et al. (1988) relatou que carboidratos produzidos nas folhas são transferidos para os ramos e então utilizados para o crescimento de vários órgãos. Em árvores caducifólias, pouco antes do início da formação das folhas, os assimilados são conduzidos para as gemas e mais tarde para as folhas jovens. Cerca de um terço das reservas acumuladas é empregado no desenvolvimento de novas folhas e no crescimento da planta. Posteriormente as reservas são distribuídas entre flores, frutos, câmbio e, por fim, para as gemas em formação e os tecidos que servem como depósito de amido nas raízes e na casca (Larcher, 2000).

$\mathrm{Na}$ literatura encontram-se trabalhos relacionando ferrugem do pessegueiro e fungicidas para o seu controle (Martins, 1994; Teviotdale et al., 1994; Carvalho et al., 2002; Citadin et al., 2005). Entretanto, são poucos os que avaliam às conseqüências da desfolha provocada pela ferrugem relacionando-a com a concentração de carboidratos solúveis totais e período de pulverização. Neste contexto os objetivos deste trabalho foram verificar as conseqüências da ferrugem na desfolha e na produção de carboidratos totais em gemas e ramos, nas condições climáticas do sul do Paraná.

\section{MATERIAL E MÉTODOS}

\section{Experimento de campo}

O estudo foi conduzido na Fazenda Experimental Gralha Azul, a qual está situada no município de Fazenda Rio Grande, região metropolitana de Curitiba PR, em duas safras consecutivas (2004 e 2005), em pomar de pessegueiro "Chimarrita", constituído de 120 plantas com nove anos de idade, espaçamento $4,5 \times 2 \mathrm{~m}$. As plantas foram divididas em 24 parcelas com cinco árvores em cada, e a avaliação foi realizada na planta central de cada parcela. O delineamento experimental utilizado foi inteiramente casualizado com quatro tratamentos e seis repetições. Os tratamentos foram: Testemunha (sem pulverização) e pulverizações realizadas de dezembro até janeiro, de dezembro até fevereiro, e de dezembro até abril, com fungicida mancozebe $(200 \mathrm{~g} / 100 \mathrm{~L}$ de água) em intervalos de 15 e 10 dias no primeiro e segundo ano respectivamente. $\mathrm{O}$ volume de calda foi de $600 \mathrm{~L} / \mathrm{ha}$, que correspondeu a $1,85 \mathrm{~L}$ por árvore, utilizando-se pulverizador tratorizado com bicos tipo cônico.

\section{Avaliações da ferrugem e da desfolha na planta}

As avaliações foram realizadas nos intervalos das pulverizações, marcando-se dois ramos mistos de um ano em lados opostos das árvores e voltados para as entrelinhas no terço mediano da planta. Nestes ramos avaliaram-se o número de folhas, a incidência e a severidade da ferrugem em oito avaliações de janeiro a maio de cada ano.

A porcentagem de incidência foi calculada relacionando o número de folhas com sintomas de ferrugem com o número total de folhas dos dois ramos marcados por parcela. Para a severidade, foi utilizada escala diagramática desenvolvida por Martins (1994) modificada com 5 níveis de severidade $(0.0,0.8,2.4,4.5,13.7)$ de área foliar afetada considerando-se a média da severidade entre as folhas dos ramos como severidade da parcela. A desfolha foi calculada pela diferença de folhas caídas entre a primeira avaliação, realizada em janeiro (máximo de enfolhamento) e cada avaliação subseqüente até final de abril. Os dados de severidade e incidência foram integralizados no tempo e transformados em AACPF (área abaixo da curva de progresso da Ferrugem). O cálculo da AACPF da severidade e incidência foi feito segundo Shaner \& Finney (1977).

\section{Avaliação de carboidratos em gemas e ramos}

Para a determinação dos carboidratos solúveis totais foram retirados aleatoriamente cinco ramos mistos, de um ano, da planta central da parcela, com comprimento entre 20 e $30 \mathrm{~cm}$ em duas épocas: em março (ramos contendo gemas) e em maio (em ramos e gemas isoladamente). As amostras (ramos com gemas) ficaram durante sete dias em temperatura ambiente para secar. Para retirada da gema foi feito um corte longitudinal entre a gema e o ramo e outro transversal no ponto de inserção da mesma com o ramo. Não foram retiradas as escamas (brácteas) que recobrem as gemas. Após a secagem, ramos e gemas foram moídos em processador doméstico, e encaminhados ao Laboratório de Ecofisiologia do Setor de Ciências Agrárias da UFPR para determinação da concentração de carboidratos solúveis totais.

A extração dos carboidratos solúveis foi feita utilizando $1,0 \mathrm{~g}$ de material seco e moído, suspenso em $10 \mathrm{~mL}$ de etanol a $80 \%$, mantido em banho-maria por 10 min. Essa operação foi repetida três vezes, filtrando-se o líquido e adicionando-se $10 \mathrm{~mL}$ de etanol ao resíduo para nova extração. O filtrado (resultado obtido nas extrações) foi colocado em estufa para evaporação da água e do etanol. $\mathrm{O}$ resíduo seco foi re-suspenso em três $\mathrm{mL}$ de água destilada e em seguida retirou-se uma alíquota de $0,1 \mathrm{~mL}$ para a dosagem de carboidratos solúveis totais.

O método utilizado para determinação de carboidratos solúveis totais foi o do fenol sulfúrico (Dubois et al., 1956). A leitura foi feita em espectrofotômetro, em comprimento de onda de $490 \mathrm{~nm}$. As dosagens de carboidratos solúveis totais, nas frações, foram obtidas de acordo com as absorbâncias e calculadas em função da curva padrão de glucose. De acordo com os rendimentos previamente obtidos calculouse a concentração de carboidratos solúveis totais em $\mathrm{mg} \cdot \mathrm{g}^{-1}$ de matéria seca do material vegetal. 


\section{Análise dos dados}

Com os dados de incidência e severidade foram plotadas as curvas de progresso da doença e os tratamentos foram submetidos à análise de variância e as médias foram comparadas pelo teste de Tukey a 5\% de probabilidade de erro, utilizando-se o programa ASSISTAT (Silva, 2006). Os dados de incidência, desfolha e severidade foram correlacionados entre si, e para os maiores valores de correlação foram realizadas análises de regressões lineares.

\section{RESULTADOS E DISCUSSÃO}

\section{Incidência e severidade de ferrugem e desfolha da planta}

Em 2004, os primeiros sintomas da ferrugem foram observados em fevereiro atingindo os máximos valores de incidência e severidade no início de abril. No ano seguinte a epidemia iniciou mais cedo, em janeiro, quando já havia mais de $25 \%$ de incidência da ferrugem no tratamento testemunha. A severidade atingiu os maiores valores em meados de março, aproximadamente um mês antes que o ano anterior (Figura 1). Devido à queda das folhas as avaliações ocorreram até 07/04 no primeiro ano e 18/03 no segundo ano. Essas diferenças podem ser devido à quantidade de inóculo disponível na área proveniente das plantas testemunhas e também a condições climáticas mais favoráveis ao desenvolvimento do fungo (Sutton, 1988). Em dezembro/03 as temperaturas mais elevadas $\left(28\right.$ a $\left.30^{\circ} \mathrm{C}\right)$ ocorreram no início do mês com precipitação abaixo de 55 $\mathrm{mm}$. Em janeiro e fevereiro/04, a variação de temperatura foi de 11 a $30^{\circ} \mathrm{C}$ e a precipitação pluviométrica de $59 \mathrm{~mm}$ e $76 \mathrm{~mm}$ respectivamente com distribuição irregular nos dois meses, o que pode explicar o atraso no início da epidemia. No segundo ano, a temperatura apresentou a mesma variação, mas a precipitação pluviométrica, em dezembro e janeiro foi $140 \mathrm{~mm}$ e $176 \mathrm{~mm}$ respectivamente (Figura 1).

Comparando-se o efeito dos tratamentos na doença, observou-se que no tratamento com pulverizações até abril houve uma menor AACPF tanto em relação à incidência como em relação à severidade (Tabela 1). Tal fato já era esperado devido ao maior período de controle da doença (de dezembro a abril) garantir maior cobertura contra o ataque do patógeno. Entretanto, ao contrário do que se supunha, este tratamento só apresentou diferença estatística em relação à testemunha não diferindo dos tratamentos que receberam pulverizações por períodos menores. Observa-se que os valores de AACPF no segundo ano foram consideravelmente maiores daqueles verificados no primeiro, evidenciando a importância de um manejo adequado para retardar a entrada do patógeno no pomar e também a sua epidemia (Tabela 1). A antecipação da epidemia aumenta a quantidade de inóculo e prejudica o controle da doença, aumentando os danos, devido à desfolha precoce.

Em relação à desfolha observou-se que no primeiro ano as plantas mantiveram o enfolhamento por mais tempo, aproximando-se do período natural de queda das folhas,
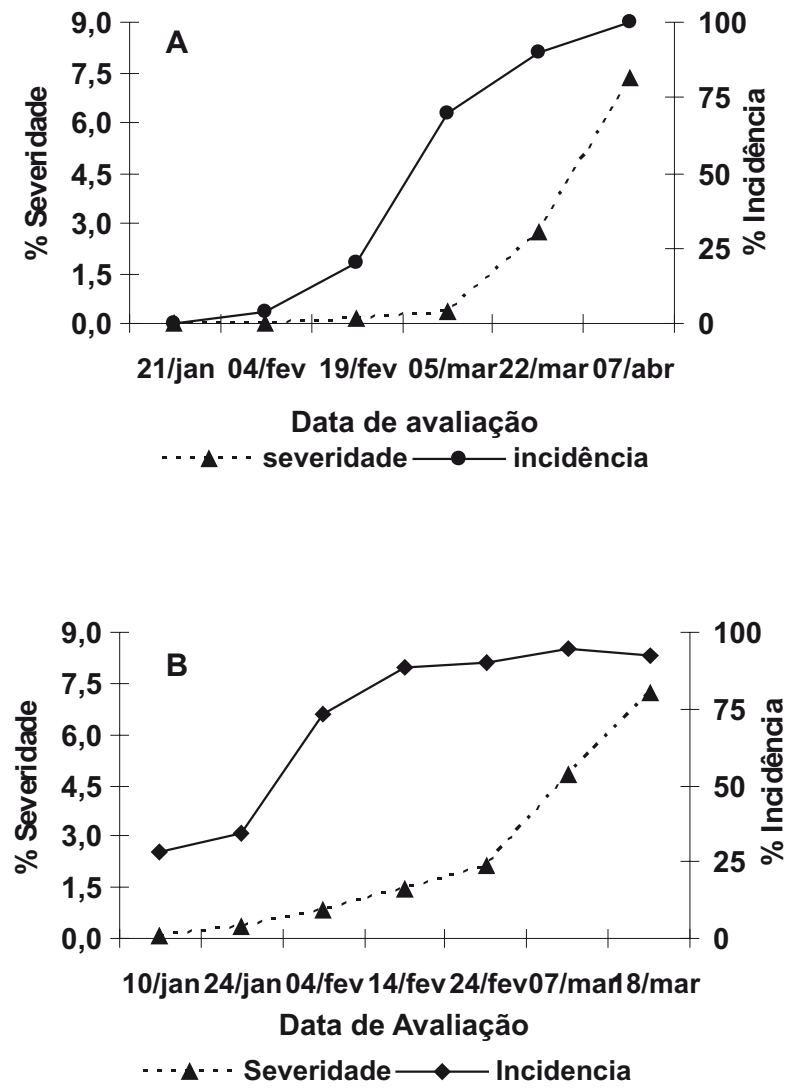

FIG. 1 - Curva de progresso da ferrugem (Tranzschelia discolor) do pessegueiro (Prunus persica) para incidência e severidade* no tratamento testemunha. Fazenda Rio Grande-PR A. Safra 2004, B. Safra 2005

*Escala de Martins (1994) modificada com 5 níveis de severidade $(0.0,0.8,2.4,4.5,13.7)$.

o qual ocorre normalmente em maio; e, no ano seguinte, devido à antecipação da doença (início em dezembro contra fevereiro), a queda das folhas foi mais precoce. Nos dois casos observaram-se diferenças evidentes e significativas na área abaixo da curva do progresso da desfolha (AACPD) entre o tratamento testemunha (sem pulverizar) e os demais (Tabela 1).

Em relação aos períodos de pulverização, a maior retenção foliar foi verificada no tratamento com pulverização até abril, mas isto não ficou evidenciado na análise estatística da AACPD (Tabela1), em contraponto a importância destas diferenças foi verificada no acúmulo de carboidratos (Tabela 2), na floração e na produtividade (Alves, 2006). Em 2005, a maior incidência da doença, verificada no início de janeiro, interferiu na antecipação da desfolha, não sendo verificadas diferenças estatísticas entre os tratamentos. Nesse ano, além do inóculo proveniente das plantas testemunhas do ano anterior, as chuvas quase diárias podem ter prejudicado a eficiência do fungicida de contato facilitando o processo de infecção do patógeno.

As variáveis AACP da incidência e AACP da severidade se correlacionaram positivamente nos dois anos, 
sendo que o coeficiente de correlação (r) apresentou valores 0.91 e 0,60 para o primeiro e segundo ano respectivamente. Isso indica que quando a epidemia é severa (segundo ano) a variável incidência tem menor importância, pois pode não discriminar os tratamentos. Na correlação entre AACP da severidade com desfolha em abril, para o primeiro ano, e até março para o segundo ano, os coeficientes de correlação foram 0,79 e 0,74 respectivamente indicando a interferência do patógeno na queda das folhas nos dois anos avaliados. A maior severidade da doença no segundo ano provocou a antecipação da desfolha (Tabela 1). Nesse mesmo período, quando a desfolha foi correlacionada com AACP da incidência, o coeficiente de correlação $(r)$ foi de 0,81 e 0,76 para o primeiro e segundo ano, respectivamente. Estes valores comprovam a necessidade de se controlar a epidemia de forma preventiva evitando a queda precoce das folhas nas plantas como também observado por Citadin et al., 2005. A interferência desta desfolha no acúmulo de carboidratos nos ramos e gemas, observada no presente trabalho (Figura 3), também foi citada por Bleicher \& Tanaka em 1982, entretanto, de forma generalizada, sem relato experimental. Em patossistemas semelhantes também se verifica a queda antecipada das folhas com alteração na reserva de nutrientes comprometendo a qualidade dos produtos. Na soja a desfolha diminui o tamanho do grão e em conseqüência reduz o rendimento (Yang et al., 1991), no álamo reduz o volume de madeira (May-De Mio et al., 2006) e no café, resulta em menor vingamento da florada, dos chumbinhos e também seca dos ramos plagiotrópicos (Zambolim et al., 1997).

Nas análises de regressão linear os coeficientes de determinação $\left(\mathrm{R}^{2}\right)$ obtidos para desfolha $\mathrm{x}$ AACP da severidade foram de 0,64, em 2004 e; 0,55, em 2005. Para AACP da severidade $x$ AACP da incidência o coeficiente foi maior em $2004(0,84)$ comparado ao de $2005(0,36)$ (Figura $2)$. Todas estas regressões foram significativas $(\mathrm{P}<0.05)$. No caso de severidades altas como se observa neste trabalho, a incidência não pode ser um parâmetro considerado para diferenciar tratamentos, como já relatado em outros trabalhos (Caieirão et al., 2001; May-De Mio et al., 2006). Da mesma forma a desfolha teve maior relação com a severidade no primeiro ano do experimento quando as diferenças eram mais evidentes, no segundo ano, com maior inóculo inicial, e a planta mais debilidade a relação fica minimizada. Neste sentido está à importância de trabalhos com fruteiras serem conduzidos durante vários anos para observar as diversas variações entre as variáveis e suas interações (Dolinski et al., 2005).

\section{Avaliação de carboidratos em gemas e ramos}

A concentração de carboidratos solúveis totais nos ramos com gemas, coletados em março, não apresentou diferenças estatísticas. Entretanto, observou-se o aumento da concentração de carboidratos conforme o período de pulverização (Tabela 2), provavelmente devido ao maior tempo de enfolhamento na planta. Dickson (1991) observou que a desfolha em plantas lenhosas leva a planta
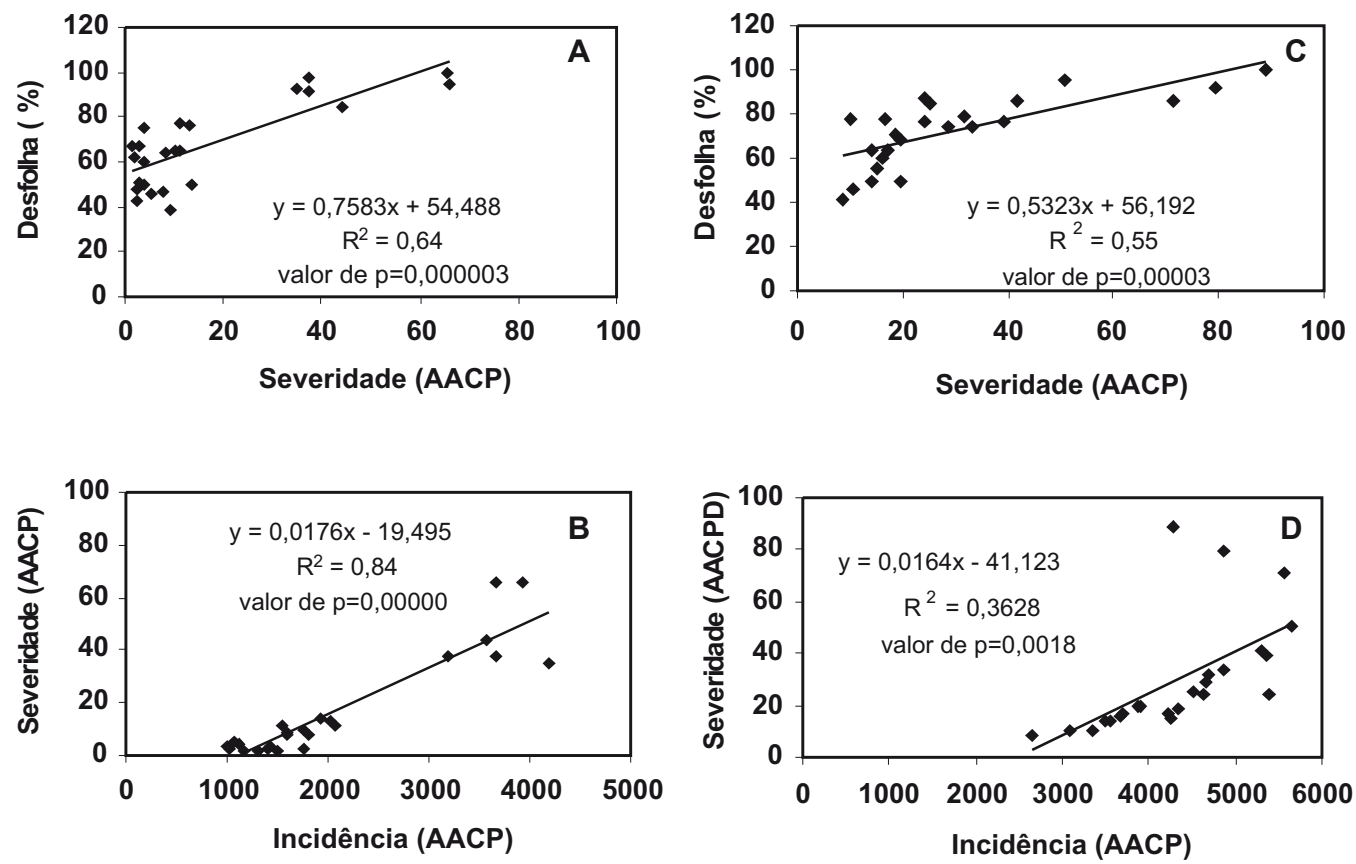

FIG. 2 - Regressão entre AACP (área abaixo da curva de progresso) da severidade e desfolha $\mathrm{A}(2004) \mathrm{C}(2005)$ e com a AACP da incidência B(2004) D(2005) da ferrugem (Tranzschelia discolor) em pessegueiro (Prunus persica) “Chimarrita”. Fazenda Rio Grande PR. 


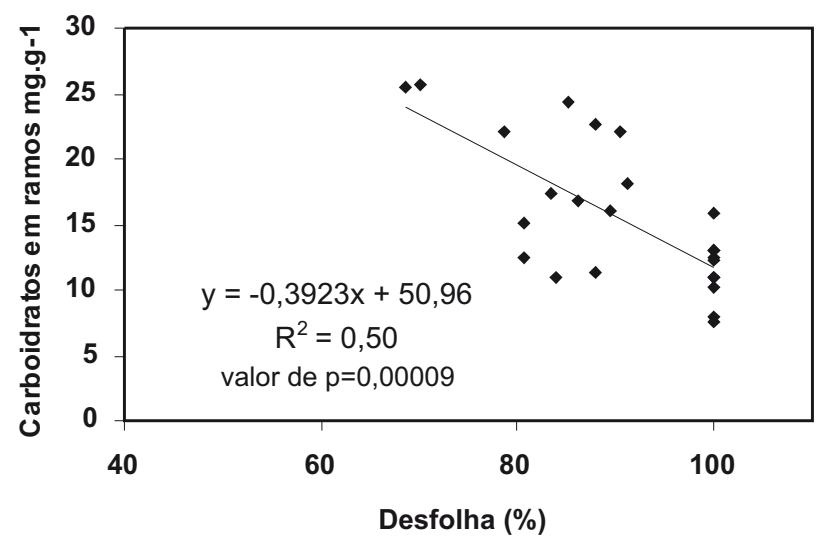

FIG. 3 - Regressão entre concentração de carboidratos solúveis totais em ramos mg.g ${ }^{-1}$ e desfolha (\%) em pessegueiro (Prunus persica) "Chimarrita". Fazenda Rio Grande PR, 2005.

TABELA 1 - AACP (área abaixo da curva de progresso) da ferrugem (Tranzschelia discolor) com base na incidência e na severidade e AACP da desfolha em pessegueiro (Prunus persica) "Chimarrita". Fazenda Rio Grande PR, 2004 e 2005

\begin{tabular}{|c|c|c|c|c|c|c|}
\hline \multirow[t]{3}{*}{ Tratamentos } & \multicolumn{6}{|c|}{ AACP } \\
\hline & \multicolumn{2}{|c|}{ Incidência } & \multicolumn{2}{|c|}{ Severidade } & \multicolumn{2}{|c|}{ Desfolha } \\
\hline & $2004^{1}$ & $2005^{2}$ & $2004^{1}$ & $2005^{2}$ & 2004 & 2005 \\
\hline Testemunha (sem pulverização) & $3706 \mathrm{~b}$ & $5171 \mathrm{~b}$ & $47,7 b$ & $59,4 \mathrm{~b}$ & $2418 \mathrm{a}$ & $3193 \mathrm{a}$ \\
\hline Pulverizado até janeiro (dez. a jan.) & $1670 \mathrm{a}$ & $4390 \mathrm{ab}$ & $9,3 \mathrm{a}$ & $25,0 \mathrm{a}$ & $1610 \mathrm{~b}$ & $2370 \mathrm{~b}$ \\
\hline Pulverizado até fevereiro (dez. a fev.) & 1629 a & $4122 \mathrm{a}$ & $6,2 \mathrm{a}$ & $20,5 \mathrm{a}$ & $1389 \mathrm{~b}$ & $2256 \mathrm{~b}$ \\
\hline Pulverizado até abril (dez.a abr.) & $1205 \mathrm{a}$ & 3624 a & $3,5 \mathrm{a}$ & $14,5 \mathrm{a}$ & $1128 \mathrm{~b}$ & $2130 \mathrm{~b}$ \\
\hline $\mathrm{CV}(\%)$ & 14,34 & 14,28 & 46,8 & 47,5 & 24,3 & 28,0 \\
\hline
\end{tabular}

Médias seguidas pela mesma letra na coluna não diferem estatisticamente entre si pelo teste de Tukey a 5\% de significância para incidência e severidade e pelo teste Duncan para desfolha. ${ }^{1}$ Avaliação até 07/04/2004; ${ }^{2}$ Avaliação até 18/03/2005. *As pulverizações iniciaram-se na primeira quinzena de dezembro.

TABELA 2 - Concentração de carboidratos solúveis totais (mg. $\left.\mathrm{g}^{-1}\right)$ em segmentos de ramos, com e sem gemas, de pessegueiro (Prunus persica) "Chimarrita". Fazenda Rio Grande PR, 2005

\begin{tabular}{|c|c|c|c|}
\hline \multirow[t]{2}{*}{ Tratamentos } & \multicolumn{3}{|c|}{ Concentração de carboidratos solúveis totais $\left(\mathrm{mg.g}^{-1}\right)$} \\
\hline & $\begin{array}{l}\text { Segmentos de ramos } \\
\text { com gemas }{ }^{1}\end{array}$ & $\begin{array}{c}\text { Segmentos de ramos } \\
\text { sem gemas }\end{array}$ & Gemas $^{2}$ \\
\hline Testemunha (s/pulverização) & $20,8 \mathrm{a}$ & $10,2 \mathrm{~b}$ & $11,1 \mathrm{a}$ \\
\hline Pulverizado de dez. a janeiro & $20,9 \mathrm{a}$ & $12,8 \mathrm{~b}$ & $13,0 \mathrm{a}$ \\
\hline Pulverizado de dez. a fevereiro & $24,9 \mathrm{a}$ & $16,4 \mathrm{ab}$ & $14,7 \mathrm{a}$ \\
\hline Pulverizado de dez. a abril & $28,2 \mathrm{a}$ & $23,0 \mathrm{a}$ & $16,4 \mathrm{a}$ \\
\hline
\end{tabular}

Média de seis repetições. Letras iguais na coluna não diferem entre si pelo teste de Tukey ao nível de 5\% de probabilidade. ${ }^{1}$ Ramos coletados em março/05 ${ }^{2}$ Ramos coletados em maio/05. *As pulverizações iniciaramse na primeira quinzena de dezembro.

a menores níveis de reserva de carboidratos, aumentando a suscetibilidade a doenças e também diminuindo o crescimento das raízes no ciclo seguinte.

Para Oliveira \& Priestley (1988) as conseqüências da desfolha precoce na quantidade de reservas acumuladas depende do tempo e da intensidade. Neste trabalho esta mesma relação foi observada: os tratamentos com maior controle da ferrugem do pessegueiro e que mantiveram a folha na planta por mais tempo aumentaram os teores de fotoassimilados. 
Ferrugem do pessegueiro e seu efeito na desfolha...

A concentração de carboidratos solúveis totais para os ramos coletados em maio apresentou diferenças estatísticas entre os tratamentos (Tabela 2), demonstrando claramente a importância do enfolhamento após o período de colheita. O tratamento com pulverização até abril diferiu estaticamente da testemunha e do tratamento com pulverização até janeiro, e não apresentou diferença estatística daquele pulverizado até fevereiro. Segundo Camelatto (1990), o baixo enfolhamento reduz a fotossíntese, afetando as reservas de carboidratos da planta no início da brotação.

Outro fato bastante importante a ser considerado é que a queda precoce das folhas provocou um florescimento antecipado no final de abril, principalmente no tratamento testemunha, o que pode ter contribuído para diferenças entre os tratamentos (Alves, 2006). Essa florada além de não ser aproveitada, enfraquece a planta usando as reservas de carboidratos (Bleicher \& Tanaka, 1982).

Em relação aos carboidratos solúveis totais nas gemas (Tabela 2) dos ramos coletados em maio, não houve diferença estatística entre os tratamentos. Entretanto, mais uma vez observou-se que as concentrações foram maiores nos tratamentos com mais enfolhamento, como observado nas análises realizadas nos ramos com gemas. Similaridade entre os tratamentos pode ser devido à floração antecipada ocorrida em abril e, também por causa de escamas lignificadas que acumulam muito carboidrato (Bonhomme et al., 1999). Além disso, o material analisado ainda não tinha passado por um período de frio. Estudo realizado por Carvalho \& Zanette (2005) com macieira evidencia uma redução na concentração de carboidratos solúveis em gemas que não receberam frio suplementar.

A correlação entre concentração de carboidratos (em ramos) e desfolha em 31 de março de 2005 apresentou $r=$ $-0,71$, indicando a relação negativa entre elas, quanto mais desfolha menor a concentração de carboidratos nos ramos. A figura 3 mostra que o coeficiente de determinação, entre as mesmas variáveis, é de $\mathrm{R}^{2}=0,50$; quando se considera as médias dos tratamentos, esse valor passa para 0,88. Estudos realizados com videiras por McArtney \& Ferree (1999) mostraram que a quantidade de carboidratos é proporcional a de massa foliar. Em pessegueiro, os carboidratos totais acumulam-se nos ramos até pouco depois da queda das folhas atingindo um máximo na metade do período de repouso (Flore \& Layne, 1996) o que, para a variedade Chimarrita, nas condições do sul do Paraná, situa-se entre os meses de maio a julho. Tal afirmação corrobora os resultados obtidos no presente trabalho.

De uma maneira geral, recomenda-se que outras análises sejam feitas considerando as contribuições deste trabalho como, por exemplo, estudos por períodos mais longos e avaliação de produtividade e demais características fitotécnicas, tais como comprimento e espessura de ramos, diâmetro do tronco, dormência etc. Em relação ao patógeno recomendam-se maiores estudos com sobrevivência em ramos e, distribuição da doença na planta. Outra possibilidade seria observar a concentração de carboidratos nas raízes
(Borba et al., 2005; Carvalho et al., 1998), e também na copa em diferentes estádios fenológicos da planta.

\section{REFERÊNCIAS BIBLIOGRÁFICAS}

Alves G (2006) Avaliação de danos causados pela ferrugem em pomar de pessegueiro da cultivar Chimarrita. Dissertação de Mestrado. Universidade Federal do Paraná. Curitiba PR.

Bleicher J, Tanaka H (1982) Doenças do pessegueiro no Estado de Santa Catarina. 2a Ed. Florianópolis. Empresa Catarinense de Pesquisa Agropecuária.

Bonhomme M, Rageau R, Gendraud M (1999) Dynamics of carbohydrate contents of different tissues in and near vegetative and floral peach buds during dormancy period, influence of a cold deprivation. In: International Symposium on Plant Dormancy. Angers, France. pp. 65. (Abstract)

Borba MRC, Scarpare Filho JA, Kluge RA (2005) Teores de carboidratos em pessegueiros submetidos a diferentes intensidades de poda verde em clima tropical. Revista Brasileira de Fruticultura 27:68-72.

Caierão E, Carvalho FIF, Floss EL, Chacón CDS, Lorencetti C, Marchioro V (2001) Efeito de níveis de severidade e incidência da ferrugem-da-folha e ferrugem-do-colmo no rendimento de linhagens de aveia. Pesquisa Agropecuária Brasileira 36:43-52.

Camelatto D (1990) Dormência em fruteiras de clima temperado. Horti Sul (Pelotas) 1:12-17.

Carvalho FC, Araujo Filho JA, Rego MC, Telles FFF (1998) Flutuações de carboidratos disponíveis nas raízes e no caule de marmeleiro (Croton sonderianus Muell. Arg.) Revista Brasileira de Zootecnia 27:670-675.

Carvalho VL, Gonçalves-Gervásio RCR, Santa-Cecilia LVC, Kato CM, Foureaux LV, Campelo MG (2002) Alternativas de controle da ferrugem do pessegueiro [Tranzschelia discolor (Fuckel) Tranzschel \& Litivinov]. Ciência e Agrotecnologia 26:227-231.

Carvalho RIN, Zanette F (2005) Variações do conteúdo de carboidratos em gemas e ramos de dois anos de macieira em região de baixa ocorrência de frio. Revista Brasileira de Fruticultura 27:352-355.

Citadin I, Bertuol O, Bassani MH, Sousa RN, Pinotti LCA, Soletti $\mathrm{T}$ (2005) Controle da ferrugem da folha de pessegueiro mediante pulverizações com diferentes fungicidas. Revista Brasileira de Fruticultura 27:317-319.

Dickson RE (1991) Assimilate distribution and storage. In: Raghavendra AS (Ed.) Physiology of trees. New York. J. Wiley \& Sons. pp. 51-85

Dolinski MA, Serrat BM, Motta ACV, Cuquel FL, Souza SR, May-De Mio LL, Monteiro LB (2005) Produção, teor foliar e qualidade de frutos do pessegueiro "Chimarrita" em função da adubação nitrogenada, na região da Lapa-PR. Revista Brasileira de Fruticultura 27:295-299.

Dubois M, Gilles KA, Hamilton JK, Rebers PA, Smith F (1956) Colorimetric method for determination of sugar and related substances. Analytical Chemistry 28:350-356.

Flore JA, Layne DR (1996) Prunus. In: Zamski EO, Schaffer AA (Eds.) Photoassimilate distribution in plants and crops: source-sink 
relationships. New York NY. Marcel Dekker. pp. 825-849.

Goldsworthy MC, Smith RE (1931) Studies on a rust of clingstone peaches in California. Phytopathology 2:133-168.

Larcher W (2000) Ecofisiologia vegetal. São Carlos SP. Ed. Rima. $531 \mathrm{p}$.

Martins MC (1994) Quantificação dos parâmetros monocíclicos e controle químico da ferrugem do pessegueiro. Dissertação de Mestrado. Universidade de São Paulo. ESALQ. Piracicaba SP.

Martins MC, Amorim L (1996) A ferrugem do pessegueiro. Summa Phytopathologica 22: 193-199.

McArtney SJ, Ferree DC (1999) Root and cane pruning affect vegetative development fruiting and dry-matter accumulation of grapevine. HortScience 4:617-621.

May-De Mio LL, Garrido L, Ueno B (2004) Doenças de fruteiras de caroço In: Monteiro LB, May-De Mio LL, Serrat BM, Cuquel FL (Eds.) Fruteiras de caroço: uma visão ecológica. Curitiba. UFPR. pp. 169-222.

May-De Mio LL, Amorim L, Moreira LM (2006) Progresso de epidemias e avaliação de danos da ferrugem em clones de álamo. Fitopatologia Brasileira 31:133-139.

Oliveira CM, Priestley CA (1988) Carbohydrate reserves in deciduous fruit trees. Horticultural Review 10:403-430.

Shaner G, Finney RE (1977) The effect of nitrogen fertilization on the expression of slow-mildewing resistance in Knox wheat.
Phytopathology 67:1051-1056.

Silva FAS (2006) Assistat - Assistência Estatística - Versão 7.3 beta. Campina Grande - PB. < http:// assistat.sites.uol.com.br >

Smith CO (1947) A study of Tranzschelia pruni-spinosae on Prunus species in California. Hilgardia 17:251-266.

Sutton JC (1988) Predictive value of weather variables in the epidemiology and management of foliar disease. Fitopatologia Brasileira 13:305-312.

Teviotdale BL, Harper DM, Michailides TJ, Sibbet GS (1994) Lack of effect of stone fruit rust on yield of French prune tree and survival of urediniospores of the pathogen on leaves, shoots, and buds. Plant Disease 78:141-145.

Yang XB, Tschanz AT, Dowler WM, Wang TC (1991) Development of yield loss models in relation to reductions of components of soybean infected with Phakopsora pachyrhizi. Journal of Phytopathology 81:420-1426.

Yoshioka H, Nagai K, Aoba K, Fukumoto M (1988) Seasonal changes of carbohydrates metabolism in apple trees. Scientia Horticulturae 36:219-227.

Zambolim L, Vale FXR, Pereira AA, Chaves GM (1997) Café (Coffea arabica L.), controle de doenças causadas por fungos, bactérias e vírus. In: Vale FXR, Zambolim L (Eds.) Controle de doenças de plantas. Viçosa MG. Suprema Gráfica e Editora. pp. 83-180.

Recebido 5 Setembro 2007 - Aceito 28 Outubro 2008 - TPP 7055

Editor Associado: Francisco F. Laranjeira 